\title{
PENGARUH PERIODE PEMANENAN RESIN DAMAR TERHADAP PENDAPATAN PETANI REPONG DAMAR DI PEKON LABUHAN MANDI PESISIR BARAT
}

\author{
(The Effect Of Resin Harvesting Period On Repong Damar Farmers Income In Pekon Labuhan \\ Mandi Pesisir Barat)
}

\author{
Faisal Kurniawan*, Hari Kaskoyo, Duryat, Rahmat Safe'I \\ Jurusan Kehutanan, Fakultas Pertanian, Universitas Lampung. Jl Sumantri Bojonegoro, Gedung \\ Meneng, Bandar Lampung, Lampung 35145 \\ *e-mail: faisalkrnwn20@gmail.com
}

\begin{abstract}
Repong Damar is a plot of land planted with various types of productive plants from various types of timber with economic value. The term repong damar is because the plant that is dominated by this plot of land is damar eye cat (Shorea javanica). The cat's eye resin tree (Shorea javanica) produces a type of non-wood forest product in the form of resin. Resin damar is one of the mainstay commodities which is a source of income for the community because it can produce in a short period and has sustainable management compared to other types of plants found in Repong Damar. Pesisir Barat Regency, Lampung Province. The research objective was to determine the relationship between the harvesting period and the quantity and quality of resin damar which affects the income of resin farmers in Labuhan Mandi, Pesisir Barat Regency, Lampung Province. Data collection was carried out in June-August 2020. The sampling used in this study was purposive. This method was chosen to obtain uniformity in terms of the same growing area, a form of management, and plant genetic factors. The data were taken in the form of resin/tree quantity in 3 harvesting periods, namely a) 2 weeks; b) 3 weeks; c) 4 weeks, the percentage of resin quality based on market quality, namely 1) $A B$;2) C; 3) D; 4) E; 5) ash; and the selling price of resin at the farmer level for each quality. Data analysis was performed using quantitative methods to calculate the amount of resin production, percentage of resin quality, and farmer income. The results showed that a harvest period of 4 weeks produced the highest resin quantity/month compared to a harvesting period of 3 weeks and a harvesting period of 2 weeks. The 4 week harvesting period also provides a higher percentage of $A B$ resin quality than the 3 week harvesting period and the 2 week harvesting period, therefore the 4 week harvesting period provides higher farmer income than the 3 week harvesting period and 2 week harvesting period.
\end{abstract}

Keywords: income, quality, quantity, resin damar

Abstrak
Repong Damar merupakan sebidang lahan yang ditanami oleh berbagai jenis tanaman produktif
dari berbagai jenis kayu yang bernilai ekonomis. Penyebutan repong damar karena tanaman
yang didominasi pada sebidang lahan tersebut yaitu damar mata kucing (Shorea javanica).
Pohon damar mata kucing (Shorea javanica) menghasilkan salah satu jenis hasil hutan bukan
kayu berupa resin. Resin damar merupakan salah satu komoditi andalan yang menjadi sumber
pendapatan masyarakat karena dapat menghasilkan dalam jangka waktu yang singkat dan
pengelolaan berkelanjutan dibandingkan jenis tanaman lain yang terdapat di Repong Damar.
Kabupaten Pesisir Barat, Provinsi Lampung. Tujuan penelitian adalah mengetahui hubungan
antara periode pemanenan dengan kuantitas dan kualitas resin damar yang berpengaruh
terhadap pendapatan petani damar Labuhan Mandi, Kabupaten Pesisir barat, Provinsi
Lampung. Pengumpulan data dilakukan pada bulan Juni-Agustus 2020. Sampling yang
digunakan dalam penelitian ini adalah purposive sampling. Metode ini dipilih untuk


mendapatkan keseragaman dalam hal tempat tumbuh yang sama, bentuk pengelolaan, dan faktor genetik tanaman. Data yang diambil berupa kuantitas resin/pohon pada 3 periode pemanenan yaitu a) 2 minggu; b) 3 minggu; c) 4 minggu, persentase kualitas resin berdasarkan kualitas dipasaran yaitu 1) $A B$; 2) $C$; 3) $D$; 4) $E$; 5) abu; dan harga jual resin ditingkat petani untuk masing-masing kualitas. Analisis data dilakukan dengan metode kuantitatif untuk menghitung jumlah produksi resin, persentase kualitas resin, dan pendapatan petani. Hasil menunjukan bahwa periode pemanenan 4 minggu menghasilkan kuantitas resin/bulan tertinggi dibandingkan periode pemanenan 3 minggu dan periode pemanenan 2 minggu. Periode pemanenan 4 minggu ternyata juga memberikan persentase kualitas resin AB lebih tinggi dibandingkan periode pemanenan 3 minggu dan periode pemanenan 2 minggu, oleh karena itu periode pemanenan 4 minggu memberikan pendapatan petani yang lebih tinggi dibandingkan periode pemanenan 3 minggu dan periode pemanenan 2 minggu.

Kata kunci : kualitas, kuantitas, pendapatan, resin damar

\section{PENDAHULUAN}

Repong menurut masyarakat Pesisir Barat merupakan lahan yang ditanami dan ditumbuhi berbagai jenis tanaman kayu maupun buah-buahan (Kolibur dan Hutagalung, 2016). Menurut Saputri et al. (2015) biasanya masyarakat memanfaatkan berbagai macam jenis tanaman produktif dari berbagai jenis kayu yang memiliki nilai jual. Salah satu jenis tanaman di Repong Damar yang dimanfaatkan oleh masyarakat adalah pohon damar mata kucing (Shorea javanica) yang menghasilkan resin damar. Sejalan dengan fahrizal (2017). Repong Damar merupakan hasil hutan bukan kayu (HHBK) yang masuk kedalam kategori pertanian hutan (Agro Forestry) dengan penghasilan utamanya yaitu berupa resin damar. Resin damar merupakan komoditas ekspor yang banyak dibutuhkan berbagai negara di dunia. Pemanfaatan HHBK dapat membantu meningkatkan kesejahteraan masyarakat tersebut (Safe'i et al, 2018).

Pendapatan yang didapatkan dari Repong Damar khususnya resin damar digunakan untuk memenuhi kebutuhan masyarakat baik kebutuhan pakan maupun non pangan ( Saputri et al,
2015). Sejalan dengan Bhaskara et al. (2018) pendapatan yang didapatkan masyarakat dari resin damar merupakan salah satu penghasilan utama yang memberikan penghasilan secara rutin untuk memenuhi kebutuhan keluarga. Resin damar telah memberikan peran penting bagi ekonomi regional di Lampung Barat dan bagi pendapatan masyarakat (Wijayanto, 2002). Resin damar memberikan peran penting terhadap kebutuhan masyarakat dikarenakan sebagai sumber pendapatan utama dari Repong Damar. Berdasarkan uraian diatas, maka penelitian ini dilakukan untuk melihat pendapatan petani resin damar dipengaruhi oleh periode waktu pemanenan. Tujuan penelitian adalah mengetahui pengaruh kualitas dan kuantitas resin damar terhadap pendapatan masyarakat Labuhan Mandi, Kabupaten Pesisir barat, Provinsi Lampung.

\section{METODE PENELITIAN}

Penelitian dilakukan di Pal 7 Desa Labuhan Mandi, Kecamatan Way Krui, Kabupaten Pesisir Barat. Penelitian dilaksanakan selama tiga bulan yaitu pada bulan Juni-Agustus 2020. Alat yang digunakan dalam penelitian ini adalah 
pita meter, kamera, Microsoft excel, tally sheet, dan timbangan. Objek penelitian ini adalah tegakan damar mata kucing dengan jumlah sampel pohon keseluruhan 51 pohon yang terbagi menjadi 17 sampel pohon pada setiap periode pemanenan yaitu 2 minggu, 3

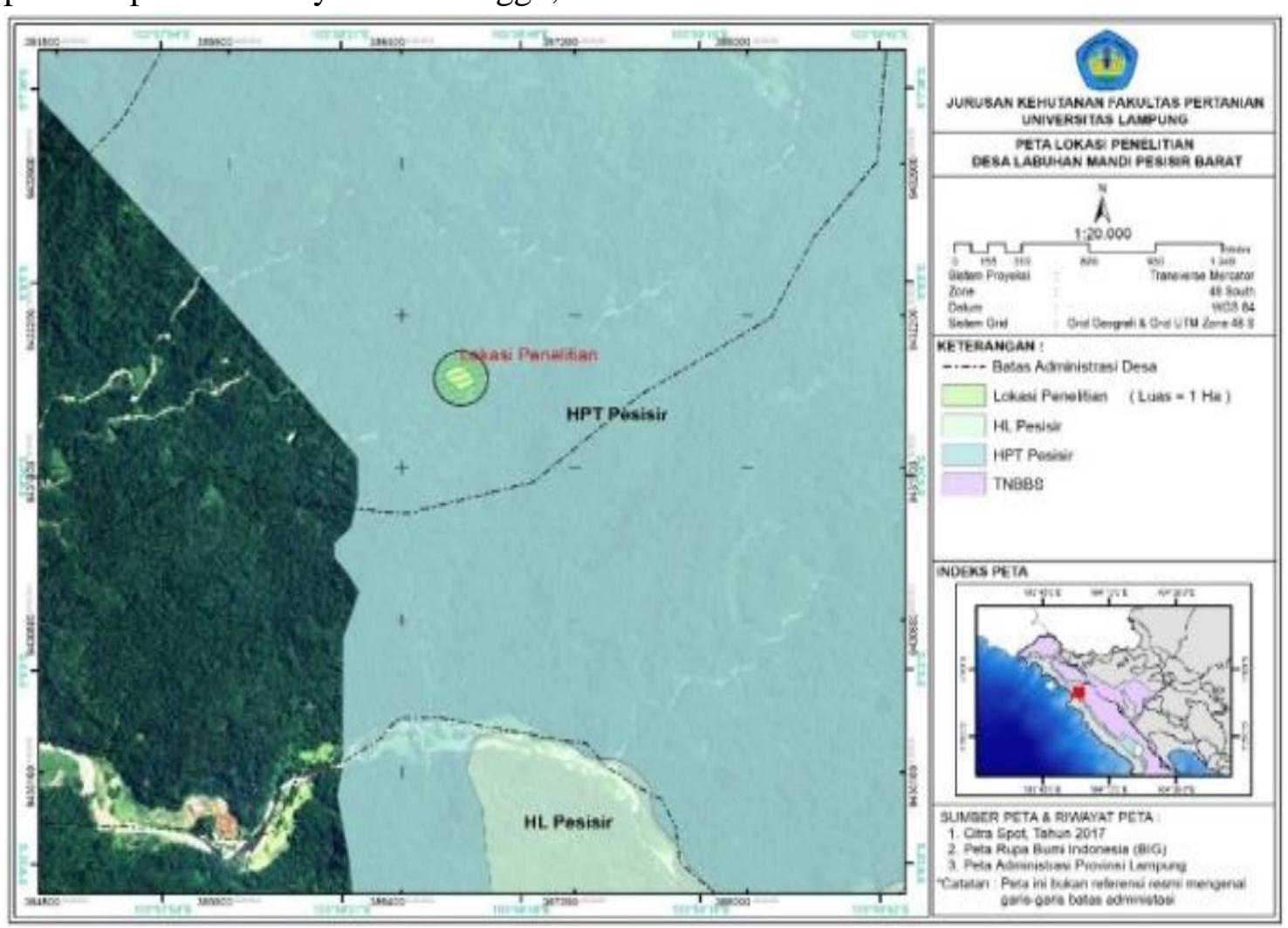

Gambar 1. Peta Lokasi Penelitian (Research location map)

Pengumpulan data dilakukan dengan metode purposive sampling. Metode ini dipilih untuk mendapatkan keseragaman dalam hal tempat tumbuh yang sama, bentuk pengelolaan, dan faktor genetik tanaman. Penelitian dilakukan pada satu bidang lahan yang dikelola oleh satu petani untuk mendapatkan hasil bahwa hanya periode pemanenan yang mempengaruhi pendapatan petani. Data yang diambil berupa kuantitas resin/pohon pada 3 periode pemanenan yaitu periode pemanenan 2 minggu, 3 minggu, dan 4 minggu, persentase minggu, dan 4 minggu. Peta lokasi penelitian ini dapat dilihat pada Gambar 1. kualitas resin berdasarkan kualitas dipasaran yaitu AB, C, D, E, dan abu, harga jual resin ditingkat petani untuk masing-masing kualitas. Analisis data menggunakan metode kuantitatif digunakan untuk mengetahui jumlah kuantitas resin, persentase kualitas resin, dan pendapatan petani. Kuantitas resin damar diperoleh dengan cara menimbang resin setiap pohon per periode waktu pemanenan. Kualitas resin damar diperoleh dengan cara menyortir resin yang telah ditimbang setiap pohon per periode waktu 
pemanenan untuk mengetahui persentase kualitas resin berdasarkan kelas kualitas resin dipasaran yaitu $\mathrm{AB}, \mathrm{C}, \mathrm{D}, \mathrm{E}$, dan abu dengan melihat tingkat kejernihan, tingkat kekerasan, tingkat kebersihan, warna, dan ukuran bongkahan. Persentase resin diperoleh dengan cara menghitung jumlah produksi resin/kelas kualitas dibagi jumlah produksi resin/pohon dikali 100\%. Melakukan wawancara salah satu tengkulak yang berada dekat dengan lokasi penelitian mengenai harga jual resin setiap kelas kualitas. Menghitung total pendapatan petani damar per tahun setiap periode pemanenan dengan cara cara mengkalikan jumlah produksi setiap kelas kualitas resin damar dengan harga jual setiap kelas kualitas per periode pemanenan, dengan menggunakan rumus sebagai berikut:

1. Persentase kualitas resin

Sumber: Arikunto (2006)

$$
\mathrm{P}=\frac{\mathrm{f}}{\mathrm{n}} \mathrm{X} 100 \%
$$

Keterangan

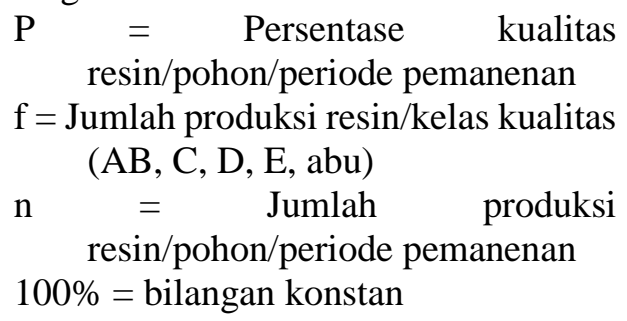

2. Jumlah rata-rata kuantitas resin

$$
\overline{\mathrm{x}}=\frac{\left(\begin{array}{c}
\mathrm{x} 1+\mathrm{x} 2+\mathrm{x} 3+\mathrm{x} 4+\mathrm{x} 5+\mathrm{x} 6+ \\
\mathrm{x} 7+\mathrm{x} 8+\mathrm{x} 9+\mathrm{x} 10+\mathrm{x} 11+ \\
\mathrm{x} 12+\mathrm{x} 13+\mathrm{x} 14+\mathrm{x} 15+\mathrm{x} 16+ \\
\mathrm{x} 17)
\end{array}\right.}{n}
$$

Keterangan

$\overline{\mathrm{x}}=$ jumlah rata-rata produksi resin setiap periode pemanenan yaitu 2 minggu, 3 minggu, 4 minggu berdasarkan kelas kualitas resin (AB, C, D, E, abu) $\mathrm{x}(1-17)=$ jumlah produksi resin setiap kelas kualitas (AB, C, D, E, abu)

$\mathrm{n}=$ jumlah sampel setiap periode pemanenan Keterangan

PKR $=$ persentase kualitas resin/pohon/periode pemanenan

JP $(\mathrm{KK})=$ jumlah produksi resin/kelas kualitas

3. Jumlah pendapatan petani

$\mathrm{P}=\mathrm{JP}(\mathrm{KK} \mathrm{AB}) \times \mathrm{H}(\mathrm{KK} \mathrm{AB})+\mathrm{JP}(\mathrm{KK}$

C) $\mathrm{xH}(\mathrm{KK} \mathrm{C})+\mathrm{JP}(\mathrm{KK} D) \times \mathrm{H}(\mathrm{KK}$

D) $+\mathrm{JP}(\mathrm{KK} D) \mathrm{xH}(\mathrm{KK} \mathrm{D})+\mathrm{JP}(\mathrm{KK}$ abu) $\times \mathrm{H}(\mathrm{KK}$ abu)

Tpt2 $=$ P2 $\times$ JMDTS2

JMDST2 $=52$ minggu $\div 2$ minggu

Tpt3= P3 $\times$ JMDTS3

JMDST3 $=52$ Minggu $\div 3$ minggu

TPt4= P4 x JMDTS4

JMDST4 $=52$ minggu $\div 4$ minggu

Keterangan:

$\mathrm{P}=$ Pendapatan petani pada periode pemanenan 2 minggu, 3 minggu, 4 minggu (Rp)

$\mathrm{JP}=$ Jumlah Produksi

KK $=$ Kelas Kualitas

JMDST2 = Jumlah minggu Dalam Satu

Tahun pada periode pemanenan 2 minggu

JMDST3 = Jumlah Minggu Dalam Satu Tahun pada periode pemanenan 3 minggu

JMDST4 = Jumlah Minggu Dalam Satu Tahun pada periode pemanenan 4 minggu

$\mathrm{H}=$ Harga jual resin setiap kelas kualitas

Tpt = Total pendapatan petani/tahun/periode pemanenan 2 minggu, 3 minggu, 4 minggu (Rp/Pohon)

\section{HASIL DAN PEMBAHASAN}

\section{Kuantitas dan Kuantitas Resin}

Damar

Periode waktu pemanenan merupakan faktor yang dapat

mempengaruhi Kuantitas dan kualitas resin damar. Semakin lama periode pemanenan maka akan semakin tinggi tingkat produktivitas yang dihasilkan. Kuantitas dan kualitas resin damar dapat dilihat pada Tabel 1. 
Tabel 1. Kuantitas dan kualitas rata-rata resin damar (The quantity and average quality of resin damar)

\begin{tabular}{|c|c|c|c|c|c|c|c|c|c|c|c|}
\hline \multirow[b]{2}{*}{$\begin{array}{c}\text { Periode } \\
\text { Pemanenan } \\
\text { (Minggu) }\end{array}$} & \multirow{2}{*}{$\begin{array}{c}\text { Kuantitas } \\
\text { Resin/ } \\
\text { Panen } \\
(\mathrm{Kg})\end{array}$} & \multicolumn{10}{|c|}{ Jumlah Produksi/Kelas Kualitas resin } \\
\hline & & $\begin{array}{c}\mathrm{AB} \\
(\mathrm{Kg})\end{array}$ & $\%$ & $\begin{array}{c}\mathrm{C} \\
(\mathrm{Kg})\end{array}$ & $\%$ & $\begin{array}{c}\mathrm{D} \\
(\mathrm{Kg})\end{array}$ & $\%$ & $\begin{array}{c}\mathrm{E} \\
(\mathrm{Kg})\end{array}$ & $\%$ & $\begin{array}{l}\mathrm{Abu} \\
(\mathrm{Kg})\end{array}$ & $\%$ \\
\hline 2 & 0,50 & 0,16 & 31,29 & 0,14 & 27,14 & 0,10 & 20,78 & 0,10 & 20,78 & 0 & 0 \\
\hline 3 & 1,05 & 0,47 & 44,97 & 0,25 & 23,32 & 0,13 & 12,53 & 0,10 & 9,59 & 0,10 & 9,59 \\
\hline 4 & 1,58 & 0,73 & 47,56 & 0,35 & 23,96 & 0,30 & 15,40 & 0,10 & 6,54 & 0,10 & 6,54 \\
\hline
\end{tabular}

Tabel 1 menunjukkan bahwa periode pemanenan berpengaruh terhadap kuantitas dan kualitas resin. Periode pemanenan 4 minggu memiliki kuantitas resin terbesar dibandingakan periode pemanenan 3 minggu dan 2 minggu. Hal ini diduga karena pelukaan pada kulit batang damar yang dapat menyebabkan resin terus mengalir hingga waktu 4 minggu sehingga kuantitas resin yang dihasilkan akan semakin besar dan kualitas resin akan semakin baik. Sejalan dengan Anasis et al. (2015) semakin lama priode pemanenan, maka getah yang dihasilkan pada suatu pohon akan semakin banyak dan kualitas getah tersebut akan semakin baik. Menurut Doan (2007) terdapat beberapa faktor penting yang dapat mempengaruhi produktivitas resin yaitu faktor biologi, tempat tumbuh, dan faktor perlakuan terhadap pohon. Sadapan merupakan salah satu perlakuan terhadap pohon yang dapat menghasilkan resin damar dengan mutu baik dan berbeda-beda. Bintoro (2020) menyatakan bahwa mutu dan kualitas getah yang dihasilkan tergantung dengan perlakuan pada pohon tersebut.

Periode pemanenan mempengaruhi persentase kualitas resin, kelas kualitas resin $(\mathrm{AB})$ memiliki persentase tertinggi pada periode 4 minggu. Hal ini diduga karena resin damar yang dibiarkan pada ruang terbuka dalam kurun waktu 4 minggu akan mengalami proses fisiologi dimana resin mengeras, tingkat kejernihan semakin baik dan berkurangnya kadar air sehingga persentase kualitas resin $(\mathrm{AB})$ tergolong tinggi. Sejalan dengan harianto et al. (2016) pemanenan resin damar setelah 1 bulan akan mengalami proses fisiologi resin yang mengeras dan tidak lengket apalagi resin tersebut dibiarkan pada lubang sadap. Menurut Evayanti et al. (2019) semakin sedikit kadar kotoran yang terdapat pada resin maka mutu resin juga semakin baik. Resin damar yang dipanen 1 bulan atau lebih memiliki kualitas yang bagus yaitu resin sudah mengeras dan telah terkumpul banyak sehingga bongkahan yang dihasilkan lebih besar, bersih dan terlihat bening jernih (Sakinah, 2006).

Berdasarkan pada tabel 1 diatas diketahui bahwa kualitas resin damar $\mathrm{E}$ memiliki jumlah produksi rata-rata pada setiap periode pemanenan yaitu $0.10 \mathrm{Kg}$ yang ternyata periode pemanenan tidak mempengaruhi jumlah produksi kelas kualitas E. Hal ini diduga karena kualitas resin damar $\mathrm{E}$ merupakan butiran kecil resin yang hancur akibat proses penyadapan. Sehingga mengakibatkan kualitas resin damar $\mathrm{E}$ menghasilkan 
jumlah produksi yang rendah. Sejalan dengan Gusti dan Zulnely (2014) resin damar yang banyak mengantung kotoran akan berdampak pada kualitas resin dan nilai jualnya yang rendah. Kualitas resin damar abu berbanding terbalik dari periode pemanenan 3 minggu dan 4 minggu karena pada periode pemanenan 2 minggu memiliki jumlah produksi $0 \mathrm{~kg}$ sedangkan periode pemanenan 3 minggu dan 4 minggu memiliki jumlah produksi $0,10 \mathrm{Kg}$. Hal ini diduga karena pada periode pemanenan 2 minggu resin damar belum mengalami pengerasan atau masih lengket sehingga kualitas resin damar abu tercampur dengan kualitas resin damar E. Beda halnya dengan periode pemanenan 3 minggu dan 4 minggu resin damar sudah mengalami pengerasan sehingga resin damar yang sudah mengeras dapat diketegorikan berdasarkan kelas kualitas resin. Sejalan dengan Gusti dan Zulnely (2014) tingginya nilai kadar abu menandakan banyaknya kotoran yang terkandung, sehingga berdampak terhadap rendahnya kualitas damar tersebut. Pengambilan resin damar kurang dari 30 hari menghasilkan resin yang masih encer, belum kering, dan terlalu lunak sehingga dapat tertempel oleh kotoran yang akan mempengaruhi kualitasnya (Sakinah, 2006).

\section{Pendapatan petani damar}

Periode pemanenan berpengaruh terhadap pendapatan petani damar. Hal ini dikarenakan semakin lama periode pemanenan maka semakin tinggi total pendapatan petani. Kualitas resin juga berpengaruh terhadap Harga jual, semakin baik kualitas resin damar, maka semakin tinggi harga jualnya sehingga harga jual juga berpegaruh terhadap pendapatan petani. Secara lengkap pengaruh periode pemanenan dan harga jual terhadap total pendapatan petani per tahun tersaji pada tabel 2.

Tabel 2. Total pendapatan rata-rata petani pertahun (The farmer's total average income for one year)

\begin{tabular}{|c|c|c|c|c|}
\hline $\begin{array}{c}\text { Periode } \\
\text { Pemanenan } \\
\text { (Minggu) }\end{array}$ & Kualitas Resin & $\begin{array}{c}\text { Rata-Rata } \\
\text { Produksi/ } \\
\text { (Kg/Minggu) }\end{array}$ & Harga (Rp/Kg) & $\begin{array}{l}\text { Total Pendapatan/Tahun } \\
\text { (Rp/Pohon) }\end{array}$ \\
\hline \multirow{5}{*}{2} & $\mathrm{AB}$ & 0,16 & 31.000 & 128.960 \\
\hline & $\mathrm{C}$ & 0,14 & 22.000 & 80.080 \\
\hline & $\mathrm{D}$ & 0,10 & 20.000 & 52.000 \\
\hline & $\mathrm{E}$ & 0,10 & 18.000 & 46.800 \\
\hline & abu & 0 & 15.000 & 0 \\
\hline \multirow{5}{*}{3} & $\mathrm{AB}$ & 0,47 & 31.000 & 247.690 \\
\hline & $\mathrm{C}$ & 0,25 & 22.000 & 93.500 \\
\hline & $\mathrm{D}$ & 0,13 & 20.000 & 44.200 \\
\hline & $\mathrm{E}$ & 0,10 & 18.000 & 30.600 \\
\hline & abu & 0,10 & 15.000 & 25.500 \\
\hline \multirow{5}{*}{4} & $\overline{\mathrm{AB}}$ & 0,73 & 31.000 & 294.190 \\
\hline & $\mathrm{C}$ & 0,35 & 22.000 & 100.100 \\
\hline & $\mathrm{D}$ & 0,30 & 20.000 & 78.000 \\
\hline & $\mathrm{E}$ & 0,10 & 18.000 & 23.400 \\
\hline & abu & 0,10 & 15.000 & 19.500 \\
\hline
\end{tabular}

(Sumber : Data Primer, 2020) 
Berdasarkan tabel 2 diketahui bahwa periode pemanenan berpengaruh terhadap total pendapatan petani per tahun. periode pemanenan 4 menghasilkan total pendapatan tertinggi petani per tahun dibandingkan periode pemnenan 2 minggu dan 3 minggu. Hal ini diduga karena periode pemanenan 4 minggu memiliki jumlah produksi yang besar dan persentase kualitas resin $\mathrm{AB}$ tertinggi. Resin tersebut sudah mengalami perubahan fisiologi yang berdampak pada kuantitas resin dan kualitas resin sehingga total pendapatan petani periode pemanenan 4 minggu lebih tinggi dibandingkan pada periode pemanenan 2 minggu dan 3 minggu. Sejalan dengan Juliantari et al. (2018) apabila, produktivitas yang dihasilkan tinggi maka tentunya pendapatan yang didapatkan juga akan semakin meningkat. Menurut Kholifah et al. (2017) jika produktivitas semakin optimal maka komoditi yang dihasilkan akan semakin besar.

Kualitas resin damar berpengaruh terhadap harga jualnya, semakin baik kualitas resin maka semakin tinggi harga jualnya sehingga berpengaruh terhadap total pendapatan petani. Hal ini diduga karena kualitas resin merupakan kualifikasi mutu produk yang dapat memenuhi kelayakan sebagai komoditi perdagangan yang berkualitas sehingga harga jual resin tinggi, hal ini juga berpengaruh terhadap total pendapatan petani per tahun semakin tinggi. Sejalan dengan harianto et al (2016) kualitas resin merupakan unsur penting dalam perdagangan damar yang dilihat dari faktor kualitas resin seperti, kebersihan, kejernihan warna, dan ukuran bongkahan. Harga resin damar dapat mempengaruhi tingkat pendapatan petani, semakin tinggi harga jual maka semakin tinggi juga tingkat pendapatan petani damar (Yulizar,2016). Wijayanto (2001) menyebutkan bahwa Repong Damar memberikan kontribusi yang besar terhadap pendapatan total rumah tangga/tahun yaitu sebesar 52\% yang mana nilai kontribusi terbesar diberikan oleh pendapatan yang diperoleh dari getah damar, yaitu sebesar 65\%. Resin damar merupakan produk utama dari Repong Damar telah memiliki tata niaga yang relatif stabil dan mapan (Wijayanto, 2002). Damar mata kucing yang dihasilkan para petani di Krui merupakan yang paling banyak dicari pengekspor, sebab resin yang dihasilkan berkualitas tinggi (Kolbinur dan hutagalung, 2016).

Petani damar biasanya melakukan pemanenan resin pada periode pemanenan kurang dari 4 minggu yang dipengaruhi oleh letak Repong Damar itu sendiri dan maraknya kasus pencurian resin damar. Hal ini sejalan dengan Yulizar (2016) Petani akan lebih sering menyadap dan mengunjungi kebun yang dekat sekitar 2-3 minggu sekali dibandingkan dengan kebun yang jauh, biasanya petani akan menyadap/memanen sekitar 1-1.5 bulan. Periode pemanenan resin damar selain karena lokasi Repong Damar juga masih rawannya pencurian resin yang terjadi sehingga petani memilih melakukan pemanenan resin kurang dari 4 minggu. Hal ini sejalan dengan (Sakinah, 2006) pencurian resin damar yang banyak terjadi menyebabkan petani memanen damarnya sebelum dicuri. Dua hal diatas 
menyebabkan kualitas resin damar yang dihasilkan rendah, kualitas resin yang rendah berpengaruh terhadap harga jualnya yang rendah.

\section{KESIMPULAN}

Periode pemanenan berpengaruh terhadap kuantitas resin, periode pemanenan 4 menghasilkan jumlah ratarata produksi sebesar (1,58 Kg/pohon/), jumlah ini lebih besar dibandingkan periode pemanenan 3 minggu (1,05 $\mathrm{Kg} /$ pohon/) dan periode pemanenan 2 minggu $(0,50 \mathrm{Kg} /$ pohon/ $) . \quad$ Periode pemanenan 4 minggu menghasilkan persentase resin dengan kualitas terbaik kelas $(A B)$ sebesar $(47,56 \%)$ lebih tinggi dibandingkan periode pemanenan 3 minggu $(44,97 \%)$ dan periode pemanenan 2 minggu (31,29\%). Periode pemanenan 4 minggu memberikan pendapatan per tahun tertinggi dengan jumlah (Rp. 515.190/pohon/tahun) dibandingkan periode pemanenan 3 minggu (Rp. 449.281/pohon/tahun) dan 2 minggu (Rp. 307.804/pohon/tahun).

\section{SARAN}

Periode pemanenan 4 minggu menghasilkan resin damar dengan jumlah terbesar dan persentase kualitas resin damar tertinggi sehingga berpengaruh terhadap pendapatan petani damar, disarankan kepada petani dan pemerintah daerah pembuat kebijakan agar pemanenan resin damar mata kucing dilakukan 4 minggu sekali.

\section{DAFTAR PUSTAKA}

Anasis, A.M. \& Sari, M.Y.A.R. 2015. Perlindungan indikasi geografis terhadap damar mata kucing (Shorea javanica) sebagai upaya pelestarian hutan (studi di Kabupaten Pesisir Barat, Propinsi Lampung). Jurnal
Hukum IUS QUIA IUSTUM, 4(2): 566-593.

Arikunto, S. 2006. Prosedur Penelitian Suatu Pendekatan Praktik Edisi Revisi VI. Buku. Rineka Cipta. Jakarta. 81hlm.

Bhaskara, D.R., Qurniati, R. \& Banuwa, I.R. 2018. Karbon tersimpan pada repong damar Pekon Pahmungan, Kecamatan Pesisir Tengah, Kabupaten Pesisir Barat. Jurnal Sylva Lestari, 6(2); 32-40.

Bintoro, A. 2020. Analisis kondisi tegakan damar (Shorea javanica) di Universitas Lampung pada masa penanaman 2005. TALENTA Conference Series: Agriculturan \& Natural Resource, 3(1):24-31.

Doan A.N.G. 2007. Ciri-Ciri Fisik Pinus (Pinus merkusii Jungh Et De Vriese) Banyak Menghasilkan Getah dan Pengaruh Pemberian Stimulansia Serta Kelas Umur Terhadap Produksi Getah Pinus di RPH Sawangan dan RPH Kemiri, KPH Kedu Selatan Perum Perhutani Unit I Jawa Tengah. skripsi. Institut Pertanian Bogor. Bogor.

Makmur, E., Imron, A. \& Maskun. 2015. Repong damar bagi masyarakat pesisir di kecamatan karya penggawa Kabupaten Pesisir Barat. Jurnal pendidikan dan penelitian sejarah, 3 (1): 1-13.

Evayanti, D., Wulandari, F.T., \& Rini, D.S. 2019. Produktivitas dan kualitas getah pinus pehutani kelas umur vii di kesatuan pengelolaan hutan Jember. Jurnal Belantara, 2(2): 127133.

Fahrizal. 2017. Analisis knowledge management system pada agroforestry Repong damar di Krui Lampung Pesisir Barat. Jurnal Ilmu Pengetahuan dan Teknologi Komputer, 3(1): 111-120. 
Gusti, R.S., \& Zulnely. 2014. Sifat fisiko kimia damar mata kucing hasil pemurnian tanpa pelarut (physico chemical properties of purified mata kucing dammar without solvent). Jurnal Penelitian Hasil Hutan, 23(3): 167-174.

Harianto, S,P., Dewi, B.S. \& Rusita. 2016. Repong Damar. Buku. Plantaxia. Yogyakarta. $259 \mathrm{hlm}$.

Juliantari, N.K.T. \& Sutrisna, I.K. 2018. Analisis faktor-faktor yang mempengaruhi produktivitas dan pendapatan petani pada pelaksanaan simantri 1di Kabupaten Badung. Ejurnal ekonomi pembangunan universitas udayana, 7 (4): 708-734.

Kholifah, U.N., Wulandari, C., Santoso, T. \& Kaskoyo, H. 2017. Kontribusi agroforestri terhadap pendapatan petani di Kelurahan Sumber Agung Kecamatan Kemiling Kota Bandar Lampung. Jurnal Sylva Lestari, 5(3): 39-47.

Kolbinur, I. \& Hutagalung, S. 2016. Analisis kebijakan pelestarian damar di Kabupaten Pesisir Barat (studi terhadap agenda setting damar sebagai usaha perlindungan dan peningkatan kesejahteraan petani damar). Jurnal Ilmiah Administrasi Publik dan Pembangunan, 7(1), 2734.

Safe'i, R., Febryano, I.G., \& Nur Aminah, L. 2018. Pengaruh Keberadaan Gapoktan Terhadap Pendapatan Petani dan Perubahan Tutupan Lahan di Hutan Kemasyarakatan. Sosiohumaniora 20(2): 109-114. DOI:

10.24198/sosiohumaniora.v20i2.143 49.

Sakinah, N. 2006. Analisis Sistem dan Tataniaga Komoditas Damar Mata Kucing (Shorea javanica) Untuk Meningkatkan Farmer Share Petani. Studi Kasus di Desa Pahmungan
Kecamatan Pesisir Tengah Kabupaten Lampung Barat Provinsi Lampung. Skripsi. Institut Pertanian Bogor. Bogor. $125 \mathrm{hlm}$.

Saputri, D.E. Bakri, S. \& Zuraida, R. 2015. Peranan sistem repong damar terhadap pendapatan, asupan makan dan status gizi balita: studi kasus di Desa Pahmungan Kecamatan Pesisir Tengah Kabupaten Pesisir Barat. Jurnal Sylva Lestari, 3(1): 63-70.

Wardah. 2005. Keanekaragaman jenis tumbuhan di kawasan hutan Krui, Taman Nasional Bukit Barisan Selatan Lampung Barat. Jurnal Teknologi Lingkungan P3TL BPPT, 6(3): 477484.

Wijayanto N. 2001. Dampak krisis ekonomi dan moneter terhadap usaha kehutanan masyarakat: Repong Damar di Pesisir Krui, Lampung, dalam Darusman D dkk. 2001. Resiliensi kehutanan masyarakat Indonesia. Yogyakarta: Debut Press. Hal 28-39.

Wijayanto N. 2002. Analisis strategi sistem pengelolaan Repong Damar di Pesisir Krui Lampung. J. Manajemen Hutan Tropika Vol VIII No. 1:39-49. Yulizar, Hikmat, A. \& Koesmaryadi, N. 2014. Konservasi damar mata kucing (Shorea javanica) berbasis masyarakat di zona tradisional Taman Nasional Bukit Barisan Selatan. Media Konservasi, 19(2); 73-80.

Yulizar. 2016. Konservasi Damar Mata Kucing (Shorea javanica) Berbasis Masyarakat di Zona Tradisional Taman Nasional Bukit Barisan Selatan. Tesis. Institut Pertanian Bogor. Bogor. $82 \mathrm{Hlm}$. 